\title{
A Pediatric Giant Phyllodes Tumor and Bloody Nipple Discharge: A Rare Case Report
}

\author{
Margherita Serra $^{1^{*}}$, Donatella Santini ${ }^{2}$, Alice Pellegrini ${ }^{1}$, Simone Zanotti ${ }^{1}$, Mario Taffurelli ${ }^{1}$
}

${ }^{1}$ Breast Centre- General Surgery, Department of the Health of Woman, Child and Urological Diseases, University of Bologna, Policlinico di Sant' Orsola, Bologna Italy

${ }^{2}$ Pathology, Department of Diagnostic and Prevention Medicine University of Bologna, Policlinico di Sant' Orsola, Bologna Italy

DOI: $\underline{10.36347 / \text { sjmcr.2020.v08i05.023 }}$

| Received: 11.05.2020 | Accepted: 18.05.2020 | Published: 27.05.2020

*Corresponding author: Margherita Serra

Abstract

Phyllodes tumor continue to provide diagnostic and therapeutic dilemmas particularly in young age. We report a rare case of phyllodes tumor of the breast (cystic-papillary variant) of a 10 years old female with bloody- monolateral nipple discharge. Only another case of giant benign phyllodes tumor in a juvenile patient with bloody nipple discharge is published in literature, but this case report deals about the youngest patient in literature.

Keywords: giant phylloides tumor, Juvenile patient, nipple discharge, pubarche, thelarche.

Copyright @ 2020: This is an open-access article distributed under the terms of the Creative Commons Attribution license which permits unrestricted use, distribution, and reproduction in any medium for non-commercial use (NonCommercial, or CC-BY-NC) provided the original author and source are credited.

\section{INTRODUCTION}

The incidence of phyllodes tumor of the breast is rare and usually it presents as a rapid growing tumor and most are benign and often they don't present nipple discharge. They generally appear in women between $20 / 35$ years of age. There is no evidence in literature of mutual relationship between precocious puberty and phyllodes tumor.

We present a case of a 10 years old female with premature pubarche and thelarche referred came to our Institute with a giant phyllodes tumor with bloody nipple unilateral discharge.

\section{Case Report}

A 10 years old female who had no mestruating came in department (Breast Unit of Policlinico di Sant'
Orsola), referring a right breast lump with an increase of volume of the gland from May to December 2014. She didn't present comorbidities and no family history of breast cancer.

The young patient presents an evidence of thelarche and pubarche at the age of 8 years old, but there was no indication to begin LH- RH analogous therapy, there wasn't an advanced bone age.

The physical examination revealed a voluminous palpable painless lump of the right breast, with blood-serum nipple discharge. The mass was 11.5 $\mathrm{cm}$ X $13.5 \mathrm{~cm} \mathrm{X} 4.8 \mathrm{~cm}$. clinically there was tension of the overlying skin, with an engorgement of the superficial vein, and the right breast was dramatically increased volume compared to controlateral breast. No axillary lymph-nodes were palpable. 


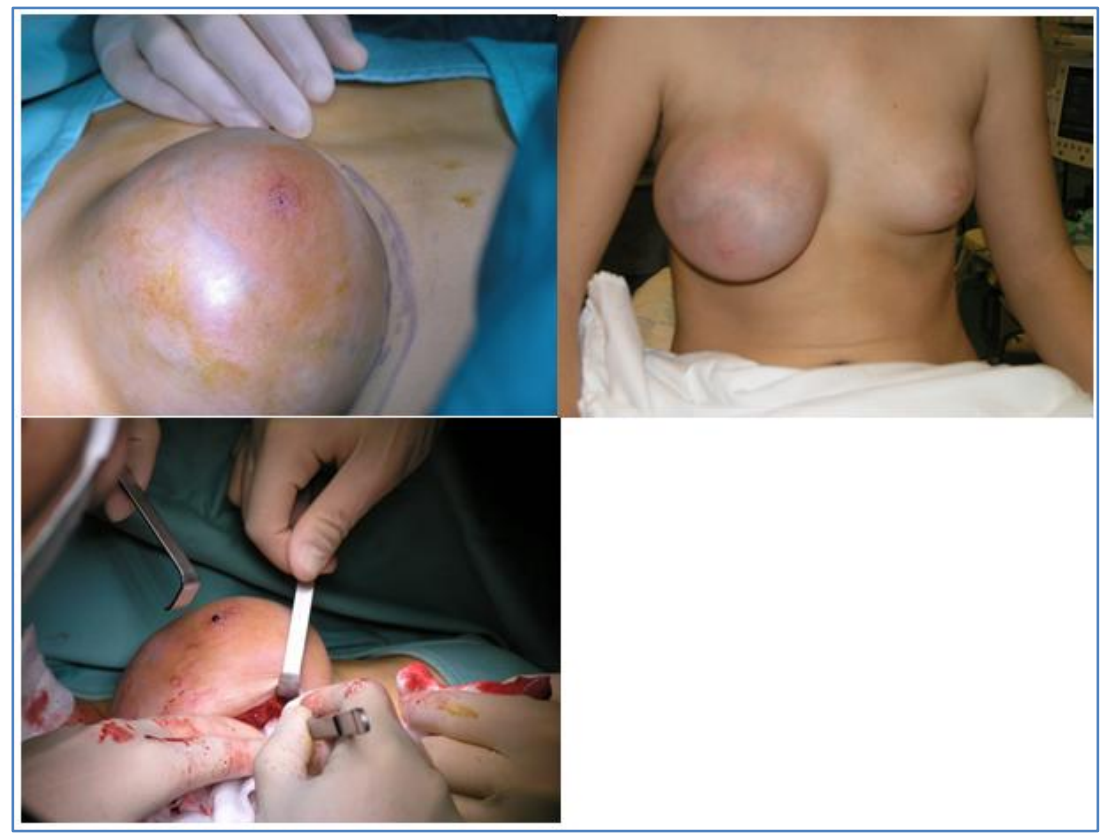

The first ultrasound test showed an increase of the volume of the gland, without clear solid or cystic lesions.

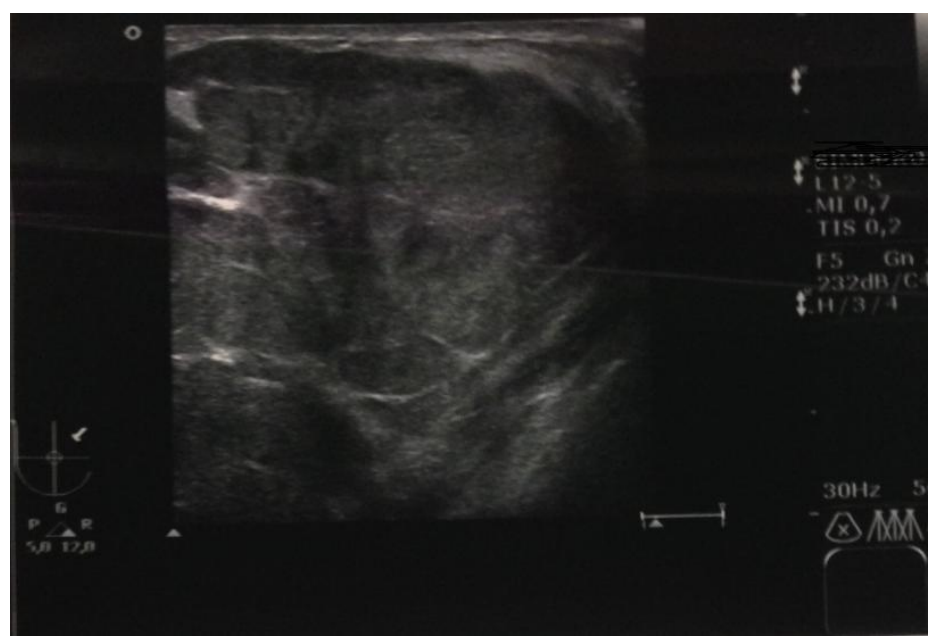

Also a second ultrasound look demonstrated inhomogeneus architecture of the gland with multiple solid isoechoic lesions.

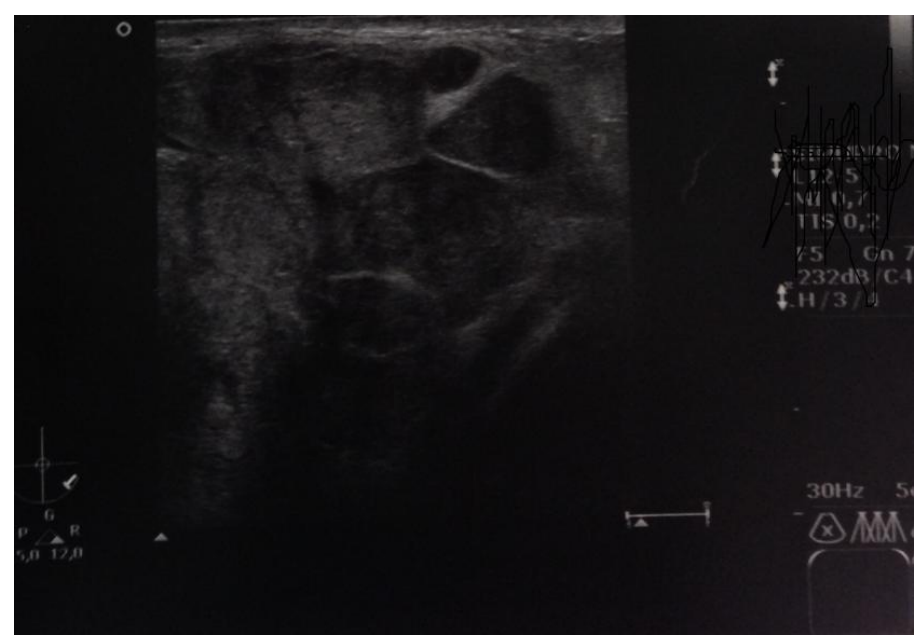


Multiple fine-needle aspirations (with a 18 Gauge needle) were performed and subsequent cytological examination revealed blood cells, extracellular mucoid material, aggregates of ductal cells with mild atypia, presence of cellular breakdown but no evidence of mitosis. It suggested that it might be a benign phylloides tumor of the breast. The cytological examination of the nipple discharge showed blood cells, granulocytes and lymphocytes, ductal cells in hyperplastic aggregates with few cytologicalarchitectural atypia.

A wide local excision under general anesthesia was performed with submammary fold incision and with preservation of the nipple-areolar complex and of the skin, and it presented as a circumscribed tumor mass with compression of the adjacent breast tissues.

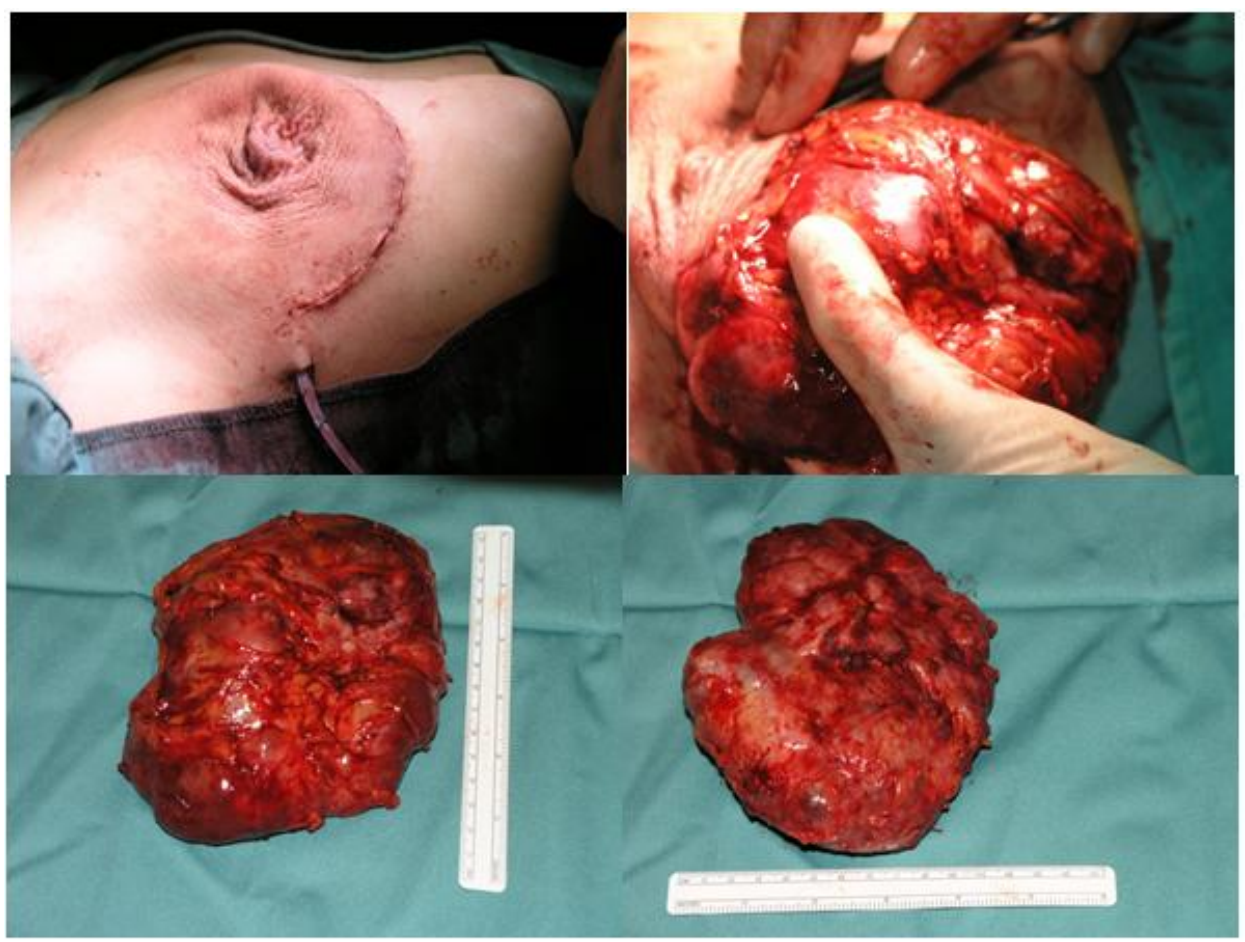

Benign Phylloides tumor cystic-papillary variant was sequently diagnosed. The macroscopic description of the specimen showed a red-whitish tumor measuring $13 \mathrm{~cm}$ in size of diameter. Histological examination revealed Fibroepithelial neoplasia, nonenveloped, multinodular growth, biphasic: component hypercellular stromal with focal aspects of so-called "overgrowth" and bland atypia, mitotic activity 4/10HPF, and epithelial component, with diffuse papillary and micropaplylic and focal hyperplasia aspects with prominent cystic component with exaggerated intracanalicular growth complex epithelial gland making papillary structures. The nipple ducts show mild periduttal phlogosis and ductal ectasia. The overall morphological picture indicates a benign cystic variant of philloid papillary tumor.

The overall morphological picture indicates a benign cystic variant of philloid tumor findings of typical benign tumor with extensive areas of hemorrhagic necrosis, ductal hyperplasia and periductal inflammation and ductal ectasia suggesting the cause of the bloody nipple discharge.

\section{Discussion AND CONCLUSIONS}

Phyllodes tumor of the breast is a rare fibroepithelial lesion (incidence $<1 \%$ of all primary breast tumors) [1-3]. They can grow quickly and when the maximum diameter is greater than $10 \mathrm{~cm}$ we talk about giant phyllodes tumors.

Phyllodes tumor was histopathological divided in three groups benign, borderline and malignant. According to the World Health Organization classifications of phyllodes tumor a criterion for malignancy is a mitotic rate higher than $10 \mathrm{X} 10$ HPF[4].

These pathological diagnoses are also based on the following criteria: tumor margins, growth of the connective tissue component, mitosis, cellular atypia and cellularity. Generally it presents as a rapidly growing breast lump and in children and adolescents are very rare. Involved surgical margins remain the most important predictor for local recurrance and re-excision is recommended in cases with a positive surgical margin and stromal overgrowth and malignancy. 
The frequency of local recurrence has varied from 8 to $46 \%$ in previous reports, and age, tumor size, surgical approach, mitotic activity, stromal overgrowth and surgical margin have been reported as prognosispredictive factors related to local recurrence [5-9].

Only two cases of benign phyllodes tumor with nipple discharge in pre-menarcal girls are reported in Literature and the clinical findings are very similar to our case $[10,11]$ and only 2 cases of malignant phyllodes [12-14].

The peculiarity of our case is that it is the youngest patient in literature with a philloid tumor, and with an association with telarche and pubarche.

Precocious puberty is the most likely cause of breast enlargement and lesions in the breast of adolescent females often require operative procedures [15]. Phyllodes tumor be always considered in the differential diagnosis of rapid growing breast lumps in females, also in young and no mestruating patients.

\section{REFFERENCE}

1. Buchanan EB, Cystosarcoma phyllodes and its surgical management. Am Surg. 1995; 61: 350-5

2. Parker SJ, Harries SA. Phyllodes tumours. Postgrad Med J. 2001; 77: 428-35

3. Chaney AW, Pollack A, Mcneese MD, Zagars GK, Pisters PW, Pollock RE, Hunt KK. Primary treatment of cystosarcoma phyllodes of the breast. Cancer: Interdisciplinary International Journal of the American Cancer Society. 2000 Oct 1;89(7):1502-11.

4. www.ncbi.nlm.nih.gov

5. De Roos WK, Kaye P, Dent DM. Factors leading to local recurrence or death after surgical resection of phyllodes tumours of the breast. British Journal of surgery. 1999 Mar;86(3):396-9.

6. Pandey M, Mathew A, Kattoor J, Abraham EK, Mathew BS, Rajan B, Nair KM. Malignant phyllodes tumor. The breast journal. 2001 Nov;7(6):411-6.

7. Zurrida S, Galimberti V, Bartoli C, de Palo G, Squicciarini P, Delledonne V, Salvadori B, Veronesi P, Bono A. Which therapy for unexpected phyllode tumour of the breast?. European Journal of Cancer. 1992 Feb 1;28(2-3):654-7.

8. Chen WH, Cheng SP, Tzen CY, Yang TL, Jeng KS, Liu CL, Liu TP. Surgical treatment of phyllodes tumors of the breast: retrospective review of 172 cases. Journal of surgical oncology. 2005 Sep 1;91(3):185-94.

9. Chaney AW, Pollack A, Mcneese MD, Zagars GK, Pisters PW, Pollock RE, Hunt KK. Primary treatment of cystosarcoma phyllodes of the breast. Cancer: Interdisciplinary International Journal of the American Cancer Society. 2000 Oct $1 ; 89(7): 1502-11$.

10. Tagaya N, Kodaira H, Kogure H, Shimizu K. A case of phyllodes tumor with bloody nipple discharge in juvenile patient. Breast Cancer. 1999 Jul 1;6(3):207-10.

11. Tagaya N, Kodaira H, Kogure H, Shimizu K. A case of phyllodes tumor with bloody nipple discharge in juvenile patient. Breast Cancer. 1999 Jul 1;6(3):207-10.

12. Sorelli PG, Thomas D, Moore A, Khan M, Hoque H. Malignant phyllodes tumor in an 11-year-old premenarchal girl. Journal of pediatric surgery. 2010 Feb 1;45(2):e17-20.

13. Sasa M, Morimoto T, Ii K, Tsuzuki H, Kamamura Y, Komaki K, Uyama T, Monden Y. A malignant phyllodes tumor of the breast in a 6-year old girl. Breast Cancer. 1995 Apr 1;2(1):71.

14. Pistolese CA, Tanga I, Cossu E, Perretta T, Yamgoue M, Bonanno E, Simonetti G. A phyllodes tumor in a child. Journal of pediatric and adolescent gynecology. 2009 Jun 1;22(3):e21-4.

15. Inder M, Vaishnav K, Mathur DR. Benign breast lesions in prepubertal female children--a study of 20 years. Journal of the Indian Medical Association. 2001 Nov;99(11):619-20. 